\title{
Validation of Nighttime Sleepability Scale Against Objective and Subjective Measures of Sleep Quality
}

\author{
Arcady A. Putilov ${ }^{1 *}$ \\ ${ }^{1}$ Research Institute for Molecular Biology and Biophysics, Novosibirsk, Russia
}

\begin{abstract}
Quick self-assessment of night sleep quality with reliable and valid instruments is often required in various fundamental and applied studies in the field of sleep medicine and chronomedicine. Individual differences in sleep quality are usually assessed with a special scale, whereas such a scale is absent in most of questionnaires for evaluation of individual differences in the domain of chronobiology. One of two exceptions is the 6-scale Sleep-Wake Pattern Assessment Questionnaire. It contains the 12 -item scale $S$ designed to self-assess nighttime sleepability. The purpose of the present report was to examine external validity of this scale by searching for correlates and predictors of $\mathrm{S}$ score. One hundred and sixty participants of sleep deprivation experiments self-reported their sleep latency, total sleep duration, nap frequency, and times for going to bed and awakening for one week prior to the experiment. Their objective and subjective sleepiness after sleepless night was measures in the course of experiment. Moreover, sleep latency and total sleep duration were measured by means of polysomnography in studies with 35 female participants. Other objective measurements included percentages of sleep stages, awakenings after sleep onset, and sleep efficiency. Additionally, sleep latencies were detected during 9 day- and nighttime 20-min napping attempts of 15 from 35 participants. It was found that significant correlates and predictors of S score include subjective and objective measures of sleep latency, percentage of slow wave sleep, subjectively and objectively assessed sleepiness, and self-reported total sleep time. These results provided solid evidence for external validity of scale S.
\end{abstract}

Keywords: Sleep quality, slow-wave sleep, sleep latency, sleep duration, sleep deprivation, questionnaire, polysomnography, MSLT

\section{INTRODUCTION}

Good sleep is absolutely crucial to the maintenance and restoration of health, but people living in the today societies often complain on disturbed night sleep. For

*Correspondence: putilovangs.ru

Dr. Arcady Putilov, 11, Nipkowstr., 12489 Berlin, Germany,

phone: 0049-30-61290031

Sleep and Hypnosis

Journal homepage:

www.sleepandhypnosis.org

ISSN:1302-1192 (Print) 2458-9101 (Online) example, approximately a half of elderly people in the United States population experiences sleep disturbances (Driscoll et al., 2008). Therefore, quick but reliable and valid self-assessment of sleep quality is of importance for various fundamental and applied studies in the field of chronomedicine and sleep medicine. Individual differences in sleep quality are usually assessed with a special uni- or multidimensional scale. The examples are the Pittsburgh Sleep Quality Index (Buysse, Reynolds, Monk, Berman, \& Kupfer, 1989) and the Epworth Sleepiness Scale (Johns, 1991). Such a scale was not included in the vast majority of questionnaires for self- 
assessment of individual differences in the domain of chronobiology. Different morningness-eveningness scales (Brown, 1993; Horne \& Ostberg, 1976; Smith, Reilly, \& Midkiff, 1989; Torsvall \& Akerstedt, 1980) and most of multidimensional questionnaires (Di Milia, Folkard, Hill, \& Walker, 2011; Di Milia, Smith, \& Folkard, 2005; Folkard, Monk, \& Lobban, 1979; Ogińska, 2011; Randler, DiazMorales, Rahafar, \& Vollmer, 2016; Roberts, 1998) can serve as examples of the questionnaires lacking a scale for night sleep self-assessment. Therefore, it is necessary to apply, at least, two questionnaire tools in order to assess individual differences in both sleep quality and chronotype. However, the 6-scale Sleep-Wake Pattern Assessment Questionnaire or SWPAQ (Putilov, 2007, 2010) and Sleep-Wake Adaptability Test (Putilov, 2016) are the exceptions because both include the $6^{\text {th }}$ scale designed for self-assessment of nighttime sleepability. The results suggesting excellent reliability of the 12-item $S$ scale of the SWPAQ were reported earlier (Putilov \& Putilov, 2005), but the results on examination of its external validity have not been reported yet.

Consequently, the aim of the present report was to provide empirical evidence for validity of scale $S$ against objective and subjective sleep measures. Since studies of intra-individual variation in self-ratings of subjective sleep quality, calmness of sleep, easiness of falling asleep, number of awakenings, sleep latency, etc. showed their significant associations with such objective measures of "better" sleep as longer sleep duration, lower number of awakenings, higher sleep efficiency, higher amount and percentage of slow wave sleep, etc. (Akerstedt, Hume, Minors, \& Waterhouse, 1994, 1997; Keklund \& Akerstedt, 1997), similar associations were expected to find in the present search for correlates and predictors of $S$ score among subjective and objective indexes of sleep deepness, latency, efficiency, duration, etc.

\section{METHODS}

Four datasets collected in two types of experimental studies were used in the present analysis for validating the scale (Tables 1 and 2). Two datasets were obtained in studies designed to objectively measure sleepiness in the course of sleep deprivation experiment, with either one or two sleepless nights ( $\mathrm{N}=130$ and 30 , respectively). Other two datasets included polysomnographic recordings of all-night sleep episode, either without or with the following 24-h testing of sleep latency by means of a slightly modified Multiple Sleep Latency Test or $\operatorname{MSLT}(\mathrm{N}=20$ and 15, respectively). All experiments were performed in accordance with the ethical standards laid down in the Declaration of Helsinki. Their protocols were approved by the Ethics Committee of the Institute. Informed written consent was obtained from each participant.

The participants of sleep deprivation experiments provided sleep history for a week prior to the experiment. Their sleepiness was measured subjectively and objectively throughout the experiment. Only a small fraction of data on such sleepiness measures was used in the present analysis and more details on applied methods were reported in the previous publications (Putilov, 2015c; Putilov \& Donskaya, 2016; Putilov, Donskaya, \& Verevkin, 2015, 2017; Putilov, Donskaya, Verevkin, \& Putilov, 2010). Each of participants denied a history of mental or sleep disorders, any current health problems, and involvement in shift work or trans-meridian flights during the preceding month. The ages of 67 male and 93 female participants of sleep deprivation studies ranged from 15 to 67 years (mean \pm standard deviation $=31.0 \pm 13.4$ ).

The participants of studies with polysomnographic nap and/or night sleep recordings were unmedicated females. They were in good general health, free of any sleep disorders, and were not engaged in shift work or long distance travel in the previous 2 months. Most of them complained on symptoms of mild or moderate depression in winter season while other participants were fully free from any types of mood and psychosomatic disorders. Only female participants were studied due to much higher prevalence of such seasonally occurring depression in female than in male adults. However, the present analysis was performed without division into the groups with and without depressive symptoms because sleep abnormalities in the participants from the former group were absent and because their objective sleep data did not correlate with mood ratings throughout the 
study, i.e., in winter and summer. The ages of 35 female participants of these studies ranged from 16 to 56 years (mean \pm standard deviation $=32.4 \pm 10.8$ ). Their polysomnographic sleep characteristics were reported in more detail in earlier publications (Palchikov, Zolotarev, Danilenko, \& Putilov, 1997; Putilov, 2015b).

The Sleep-Wake Pattern Assessment Questionnaire (Putilov, 1990, 2010) was administered, at least once, to each participant of sleep and deprivation studies to obtain self-assessment of nighttime and anytime sleepability, daytime and anytime wakeability, and evening and morning lateness ( $S, F, V, W, E$, and $M$, respectively). Score on the 12-item $S$ scale was used in a search for its correlates and predictors (Tables 1 and 2, respectively). Tables 1 and 2 contain a list of all subjective and objective measures tested as correlates and predictors.

Each morning during a week prior to the experiment, the participants of sleep deprivation experiments reported duration of their nap, sleep latency and times for going to bed and awakening. Total sleep duration was calculated as difference between these times minus sleep latency. Everyday self-reports were averaged over preexperimental week with exception of duration of nap that was transformed into a nap frequency score $(1=$ no, $2=$ once, and $3=$ more than once).

Subjective and objective sleepiness measures were added to this main list of self-reports. Subjective sleepiness was scored with the 9-step Karolinska Sleepiness Scale (KSS) (Akerstedt \& Gillberg, 1990). To measure objective sleepiness, a single electroencephalographic index named Spectral Drowsy Component Score (SDCS) was earlier introduced. Details on electroencephalographic recordings during the first minute after closing the eyes and on calculations of SDCS from these recordings were provided elsewhere (Putilov, 2015a; Putilov et al., 2017). Scorings of sleepiness obtained during the second half of the first sleepless night (i.e., 6:00 or 7:00 in one- and two-day deprivation experiments, respectively) as well as in the following morning (at 9:00 in any of these experiments) were used in the present analysis.

Polysomnographic records were obtained after an adaptation night for normally scheduled all-night sleep episode (23:00-8:00). Thereafter, recordings were continued for a subsample of 15 participants during $920-$ min sleep latency tests in daytime $(10: 00,12: 00,14: 00$, $16: 00,18: 00)$ and nighttime (23:00, 1:00, 3:00, 5:00). Sleep was allowed till the end of each of $920-\mathrm{min}$ recordings. In the course of any recording the participants were lying in bed in the darkened room of the sleep laboratory and were asked to try to fall asleep and sleep until hearing the awakening signal from the nursing staff. Such recordings were obtained, at least, twice for each participant. The interval between the first and other recordings was either one week or several months (up to a half of the year). Data were averaged for each participant. Analysis of information provided by study participants on phase of their menstrual cycle at a night of polysomnographic recordings showed that approximately the same number of records was obtained in the first, second, third, and fourth quarter of the cycle.

Sleep stages were visually scored by two independent judges. The epochs with discrepant scores were reexamined by both judges together to produce consensus scores. Each epoch of the polysomnographic record was categorized in accord with the standard criteria (Iber, Ancoli-Israel, Chesson, \& Quan, 2007 ; Rechtschaffen \& Kales, 1968) as wake, stage 1 (N1), stage 2 (N2), stages 3 and 4 (N3 or slow-wave sleep) of nonREM (non-Rapid Eye Movement) sleep, REM sleep (R), or movement. Sleep efficiency was expressed as percentage of sleep time in total bed time (the latter is time spent asleep plus total wake time).

To test significance of associations of $\mathrm{S}$ score with demographic characteristics (age and gender) and different sleep and sleepiness indexes in the whole dataset and separate samples, correlation analyses and stepwise linear regression analyses were performed (Tables 1 and 2, respectively). Level of significance was fixed at $\mathrm{p}=0.05$.

\section{RESULTS}

The results given in Tables 1 and 2 suggest that many of self-reported and objectively measured characteristics of sleep and sleepiness can serve as predictors and/or 
correlates of score on scale S. Almost every second index from the whole list of subjective and objective indexes of sleep and sleepiness correlated with $S$ score, and, importantly, these were the most expected correlates of nighttime sleepability. For instance, as it was expected the strongest correlation was shown by Stage N3 or slow-

\section{Table 1. Correlation of S score with other measures of sleep and sleepiness}

\begin{tabular}{|c|c|c|c|c|c|c|c|}
\hline Study & All & & p depriva & & & & + MSLT \\
\hline Sample size, N & $160+35$ & $130+30$ & 130 & 30 & $20+15$ & 20 & 15 \\
\hline Gender+ & $-.159 \star \star$ & $-.158^{\star}$ & $-.162^{\star}$ & -.136 & - & - & - \\
\hline Age & $-.370 * \star \star$ & 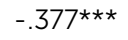 & $-.441 * \star \star$ & $-.365^{\star}$ & -.322 & -.331 & -.317 \\
\hline Total sleep time & $.166^{\star}$ & $.181^{\star}$ & .109 & $.486^{\star \star}$ & .018 & .187 & -.178 \\
\hline $\mathrm{SL}, \min ^{\wedge}$ & $-.481^{\star * \star}$ & $-.507 * * *$ & $-.462^{\star \star \star}$ & $-.745^{\star \star *}$ & $-.336^{\star}$ & -.134 & $-.532^{\star}$ \\
\hline Go to bed & - & .135 & .164 & .092 & - & - & - \\
\hline Awakening & - & .154 & .146 & .231 & - & - & - \\
\hline Napping score ${ }^{+}$ & - & .006 & .040 & -.145 & - & - & - \\
\hline KSS $6: 00$ or $7: 00$ & - & .014 & .096 & -.137 & - & - & - \\
\hline KSS 9:00 & - & .143 & $.206^{*}$ & .061 & - & - & - \\
\hline SDCS $6: 00$ or $7: 00$ & - & $.169 *$ & $.181^{\star}$ & $.390 *$ & - & - & - \\
\hline SDCS 9:00 & - & $.180^{*}$ & $.209 *$ & $.430 *$ & - & - & - \\
\hline Wake, min & - & - & - & - & .176 & .063 & .507 \\
\hline Sleep efficiency, \% & - & - & - & - & .003 & .023 & -.011 \\
\hline Stage N1, \% & - & - & - & - & -.047 & .000 & -.216 \\
\hline Stage N2, \% & - & - & - & - & -.061 & .109 & -.299 \\
\hline Stage N3, \% & - & - & - & - & $.374^{\star}$ & .310 & .460 \\
\hline Stage R, \% & - & - & - & - & -.163 & -.232 & -.095 \\
\hline Multiple SL, min & - & - & - & - & - & - & $-.702^{* *}$ \\
\hline
\end{tabular}

Notes. SL: Latency to stage N1 sleep; Total sleep time: Difference between times for awakening and sleep onset calculated by adding SL to time of going to bed; Napping score: $0=$ none, $1=$ once, and 2=more than once; KSS: Subjective sleepiness measured as score on the Karolinska sleepiness scale (Akerstedt 8 Gillberg, 1990); SDCS: Objective sleepiness measured with the EEG index named "Spectral Drowsy Component Score" (Putilov, 2015a; Putilov et al., 2017); Multiple SL, min: Mean SL for daytime and nighttime 20-min napping attempts scheduled at 10:00, 12:00, 14:00, 16:00, 18:00, 23:00, 1:00, 3:00, and 5:00 (MSLT). ^SL and Total sleep time, min, were determined either subjectively or objectively in Sleep deprivation or Night sleep studies, respectively. ${ }^{+}$The Kendall's Tau, otherwise the Pearson coefficients of correlation. Level of significance for coefficient of correlation: ${ }^{* *}(p<0.001){ }^{* *}(p<0.01),{ }^{*}(p<0.05)$.

\section{Table 2. Stepwise linear regression analysis aimed on prediction of S score}

\begin{tabular}{|c|c|c|c|c|c|c|c|}
\hline \multirow{2}{*}{$\frac{\text { Study }}{\text { Sample size, N }}$} & \multirow{2}{*}{$\begin{array}{c}\text { All } \\
195\end{array}$} & \multicolumn{3}{|c|}{ Sleep deprivation } & \multicolumn{2}{|c|}{ Night sleep } & \multirow{2}{*}{$\frac{+ \text { MSLT }}{15}$} \\
\hline & & $130+30$ & 130 & 30 & $20+15$ & 15 & \\
\hline $\mathrm{R}^{2}$ & .334 & .358 & .397 & .446 & .284 & .283 & .492 \\
\hline F-ratio (ANOVA) & $48.3^{* * *}$ & $43.7^{\star * *}$ & $27.7^{* \star *}$ & $24.7^{* * *}$ & $6.3^{\star \star}$ & $5.1^{*}$ & 12.6 ** \\
\hline
\end{tabular}

\begin{tabular}{|c|c|c|c|c|c|c|c|}
\hline Gender & -.147 & -.126 & -.118 & -.085 & - & - & - \\
\hline Age & 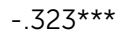 & $-.320 \star \star \star$ & $-.385^{\star \star \star}$ & -.062 & -.135 & -.251 & -.237 \\
\hline Total sleep time ${ }^{\wedge}$ & .039 & .052 & -.005 & $.313^{*}$ & -.163 & -.104 & -.189 \\
\hline $\mathrm{SL}, \min ^{\wedge}$ & $-.447 * * \star$ & $-.468 * * *$ & $-.431^{* \star \star}$ & $-.664^{* * *}$ & $-.381^{*}$ & $-.532^{\star}$ & -.003 \\
\hline Go to bed & - & -.032 & -.118 & .064 & - & - & - \\
\hline Awakening & - & .011 & -.095 & .100 & - & - & - \\
\hline Napping score & - & -.043 & -.055 & -.020 & - & - & - \\
\hline KSS 6:00/7:00 & - & -.047 & -.034 & .092 & - & - & - \\
\hline KSS 9:00 & - & .094 & $.139 *$ & .189 & - & - & - \\
\hline SDCS 6:00/7:00 & - & .006 & .087 & .090 & - & - & - \\
\hline SDCS 9:00 & - & .006 & .088 & .063 & - & - & - \\
\hline Wake, min & - & - & - & - & .138 & .328 & .147 \\
\hline Sleep efficiency, \% & - & - & - & - & -.046 & -.092 & -.184 \\
\hline Stage N1, \% & - & - & - & - & .070 & .068 & .026 \\
\hline Stage N2, \% & - & - & - & - & .318 & -.353 & -.143 \\
\hline Stage N3, \% & - & - & - & - & $.416^{\star *}$ & .386 & .229 \\
\hline Stage REM, \% & - & - & - & - & -.099 & .006 & -.085 \\
\hline Multiple SL, min & - & - & - & - & - & - & $-.702^{\star *}$ \\
\hline
\end{tabular}

Notes. Level of significance for either F-ratio (ANOVA) or t-value (beta): ${ }^{* \star *}(p<0.001),{ }^{* *}(p<0.01),{ }^{*}(p<0.05)$. See also notes to Table 1 . 
wave sleep that is also often referred to as deep sleep but not by "lighter" sleep stages, such as N1, N2, and R.

However, some of correlation coefficients did not reach a statistically significant level due to a relatively small sample size. The example is the sample of 20 female participants without MSLT (Table 1). Therefore, the results of regression analyses were negative for this sample, and they are not included in Table 2. Instead, the results of two such analyses for another sample of 15 female participants are included, either with or without adding data on MSLT in the analyzed set of variables (Table 2). In general, the regression analyses confirmed the results of correlation analyses. They yielded such predictors of $S$ score as subjective and objective measures of sleep latency, percentage of slow wave sleep, subjectively assessed sleepiness, and self-reported total sleep time. For instance, it was found that individual variance in sleep latency explained from a quarter to a half of total individual variance in $S$ score (Table 2).

\section{DISCUSSION}

It is believed that good sleep is absolutely crucial for health, but people of the today post-industrial societies often suffer from insufficient sleep quality. In the fundamental and applied studies of these people in the field of sleep medicine and chronomedicine a quick selfassessment of both night sleep quality and chronotype is often required. The assessment can be done by applying two separate questionnaire instruments. However, the 6-scale SWPAQ (Putilov, 2007, 2010) is designed for selfassessment of both chronotype and nighttime sleep quality. If the estimates of reliability of the 12-item $S$ scale for selfassessment of nighttime sleepability were earlier reported (Putilov \& Putilov, 2005), the present analysis reports for the first time the results of examination of its external validity against objective sleep and sleepiness measures.

A set of significant correlates of $S$ score was identified. It included subjective and objective measures of sleep latency, percentage of slow wave sleep, subjectively and objectively assessed sleepiness, and self-reported total sleep time. These significant correlations were further supported by means of stepwise linear regression analysis.
These results allow the conclusion that both correlation and regression analyses provided solid evidence for external validity of scale $S$.

Our studies have several limitations. For instance, the deprivation experiments were not designed to measure objective characteristics of pre-experimental sleep-wake cycles. Therefore, self-reports on sleep latency, total sleep time, etc. were not confirmed by polysomnographic results. Moreover, nap and sleep polysomnographic recordings were obtained only from female participants. The majority of these participants provided S score only once whereas their polysomnographic recordings were obtained more than once and the interval between them was sometimes as long as a half of the year. A possibility of change in $S$ score on this interval was not tested for each study participant. Therefore, it has to be emphasized that some of the present results on external validity of scale $S$ desire further confirmation.

\section{CONCLUSION}

The present results supported validity of nighttime sleepability scale $S$. They, in particular, revealed significant associations of $S$ score with subjective and objective measures of sleep latency and sleepiness after sleepless night, objective index of sleep deepness, and selfreported duration of night sleep.

\section{Conflict of interest}

No potential conflict of interest was reported by the author.

\section{Acknowledgement}

The experiments were supported by the Russian Foundation for Basic Research (grants 07-06-00263-a, 1006-00114-a, 13-06-00042-a, and 16-06-00235-a) and the Russian Foundation for Humanities (grants 06-06-00375a, 12-06-18001-e, and 15-06-10403-a). The author is indebted to Dr. Vladislav Palchikov, Dmitriy Zolotarev (Hefelle), Andrey Abelev, Valery Kozaruk, Andrey Samsonov, Dr. Konstantin Danilenko, Olga Donskaya, and Dr. Evgeniy Verevkin for their valuable help in collection of experimental datasets. 


\section{References}

Akerstedt, T., \& Gillberg, M. (1990). Subjective and objective sleepiness in the active individual. International Journal of Neuroscience, 52(1-2), 29-37.

Akerstedt, T., Hume, K., Minors, D., \& Waterhouse, J. (1994). The meaning of good sleep : A longitudinal-study of polysomnography and subjective sleep quality. Journal of Sleep Research, 3(3), 152158

Akerstedt, T., Hume, K., Minors, D., \& Waterhouse, J. (1997). Good sleep : Its timing and physiological sleep characteristics. Journal of Sleep Research, 6(4), 221-229.

Brown, F. M. (1993). Psychometric equivalence of an improved Basic Language Morningness (BALM) Scale using industrialpopulation within comparisons. Ergonomics, 36(1-3), 191-197.

Buysse, D. J., Reynolds, C. F., Monk, T. H., Berman, S. R., \& Kupfer, D. J. (1989). The Pittsburgh Sleep Quality Index: A new instrument for psychiatric practice and research. Psychiatry Research, 28(2), 193-213.

Di Milia, L., Folkard, S., Hill, J., \& Walker, C. (2011). A psychometric assessment of the Circadian Amplitude and Phase Scale. Chronobiology International, 28(1), 81-87.

Di Milia, L., Smith, P. A., \& Folkard, S. (2005). A validation of the revised circadian type inventory in a working sample. Personality and Individual Differences, 39(7), 1293-1305.

Driscoll, H. C., Serody, L., Patrick, S., Maurer, J., Bensas, S., Houck, P. R., et al. (2008). Sleeping well, aging well: A descriptive and cross-sectional study of sleep in "Successful Agers" 75 and older. American Journal of Geriatric Psychiatry, 16(1), 74-82.

Folkard, S., Monk, T. H., \& Lobban, M. C. (1979). Towards a predictive test of adjustment to shift work. Ergonomics, 22(1), 7991.

Horne, J. A., \& Ostberg, O. (1976). A self-assessment questionnaire to determine morningness-eveningness in human circadian rhythms. International Journal of Chronobiology, 4(2), 97-110.

Iber, C., Ancoli-Israel, S., Chesson, A. L., \& Quan, S. F. (2007). The AASM manual for the scoring of sleep and associated events: Rules, terminology and technical specifications. Westchester, IL: American Association of Sleep Medicine.

Johns, M. W. (1991). A new method for measuring daytime sleepiness : the Epworth Sleepiness Scale. Sleep, 14(6), 540-545.

Keklund, G., \& Akerstedt, T. (1997). Objective components of individual differences in subjective sleep quality. Journal of Sleep Research, 6(4), 217-220.

Ogińska, H. (2011). Can you feel the rhythm? A short questionnaire to describe two dimensions of chronotype. Personality and Individual Differences, 50(7), 1039-1043.

Palchikov, V. E., Zolotarev, D. Y., Danilenko, K. V., \& Putilov, A. A. (1997). Effects of the seasons and of bright light administered at different times of day on sleep EEG and mood in patients with seasonal affective disorder. Biological Rhythm Research, 28(2), 166-184.

Putilov, A. A. (1990). A questionnaire for self-assessment of individual traits of sleep-wake cycle. Bull Siberian Branch of the USSR Academy of Medical Sciences, 1, 22-25 [in Russian].

Putilov, A. A. (2007). Introduction of the tetra-circumplex criterion for comparison of the actual and theoretical structures of the sleep-wake adaptability. Biological Rhythm Research, 38(1), 65-84.
Putilov, A. A. (2010). Geometry of individual variation in personality and sleep-wake adaptability. New York, NY: Nova Science Pub Inc.

Putilov, A. A. (2015a). Can sleepiness be evaluated quickly, directly, objectively, and in absolute terms? Scoring of alert/drowsy components of the resting electroencephalogram spectrum. Somnologie, 19(3), 193-204

Putilov, A. A. (2015b). Physiological sleep propensity might be unaffected by significant variations in self-reported well-being, activity, and mood. Sleep Disorders, 2015.

Putilov, A. A. (2015c). Principal component scoring of the resting EEG spectrum provides further evidence for age-associated disinhibition of the wake drive. Healthy Aging Research, 4(35), 1-9. Putilov, A. A. (2016). Three-dimensional structural representation of the sleep-wake adaptability. Chronobiology International, 33(2), 169-180.

Putilov, A. A., \& Donskaya, O. G. (2016). Evidence for ageassociated disinhibition of the wake drive provided by scoring principal components of the resting EEG spectrum in sleepprovoking conditions. Chronobiology International, 33(8), $995-$ 1008.

Putilov, A. A., Donskaya, O. G., \& Verevkin, E. G. (2015). How many diurnal types are there? A search for two further "bird species". Personality and Individual Differences, 72, 12-17.

Putilov, A. A., Donskaya, O. G., \& Verevkin, E. G. (2017). Generalizability of frequency weighting curve for extraction of spectral drowsy component from the EEG signals recorded in eyes-closed condition. Clinical EEG and Neuroscience, 48.

Putilov, A. A., Donskaya, O. G., Verevkin, E. G., \& Putilov, D. A. (2010). Associations of waking EEG structure with chronotype and trototype of 130 sleep deprived individuals. Biological Rhythm Research, 41(2), 113-136.

Putilov, A. A., \& Putilov, D. A. (2005). Sleepless in Siberia and Alaska: Cross-validation of factor structure of the individual adaptability of the sleep-wake cycle. Ergonomia, 27(3), 207-226.

Randler, C., Diaz-Morales, J. F., Rahafar, A., \& Vollmer, C. (2016). Morningness-eveningness and amplitude - development and validation of an improved composite scale to measure circadian preference and stability (MESSi). Chronobiology International, 33(7), 832-848.

Rechtschaffen, A., \& Kales, A. (1968). A manual of standardized terminology, techniques and scoring system for sleep stages of human subjects. Los Angeles, LA: UCLA Brain Information Service/ Brain Research Institute.

Roberts, R. D. (1998). The lark-owl (chronotype) indicator (LOCI) Sydney, Australia: Entelligent Testing Products.

Smith, C. S., Reilly, C., \& Midkiff, K. (1989). Evaluation of three circadian rhythm questionnaires with suggestions for an improved measure of morningness. Journal of Applied Psychology, 74(5), 728.

Torsvall, L., \& Akerstedt, T. (1980). A Diurnal Type Scale : Construction, consistency and validation in shift work. Scandinavian Journal of Work Environment \& Health, 6(4), 283290. 